\title{
Computational Screening of MOF-Based Mixed Matrix Membranes for $\mathrm{CO}_{2} / \mathrm{N}_{2}$ Separations
}

\author{
Zeynep Sumer and Seda Keskin \\ Department of Chemical and Biological Engineering, Koc University, Rumelifeneri Yolu, Sariyer, 34450 Istanbul, Turkey \\ Correspondence should be addressed to Seda Keskin; skeskin@ku.edu.tr
}

Received 11 April 2016; Accepted 9 May 2016

Academic Editor: Pushpendra Kumar

Copyright (C) 2016 Z. Sumer and S. Keskin. This is an open access article distributed under the Creative Commons Attribution License, which permits unrestricted use, distribution, and reproduction in any medium, provided the original work is properly cited.

\begin{abstract}
Atomically detailed simulations were used to examine $\mathrm{CO}_{2} / \mathrm{N}_{2}$ separation potential of metal organic framework- (MOF-) based mixed matrix membranes (MMMs) in this study. Gas permeability and selectivity of 700 new MMMs composed of 70 different MOFs and 10 different polymers were calculated for $\mathrm{CO}_{2} / \mathrm{N}_{2}$ separation. This is the largest number of MOF-based MMMs for which computational screening is done to date. Selecting the appropriate MOFs as filler particles in polymers resulted in MMMs that have higher $\mathrm{CO}_{2} / \mathrm{N}_{2}$ selectivities and higher $\mathrm{CO}_{2}$ permeabilities compared to pure polymer membranes. We showed that, for polymers that have low $\mathrm{CO}_{2}$ permeabilities but high $\mathrm{CO}_{2}$ selectivities, the identity of the MOF used as filler is not important. All MOFs enhanced the $\mathrm{CO}_{2}$ permeabilities of this type of polymers without changing their selectivities. Several MOF-based MMMs were identified to exceed the upper bound established for polymers. The methods we introduced in this study will create many opportunities to select the $\mathrm{MOF} /$ polymer combinations with useful properties for $\mathrm{CO}_{2}$ separation applications.
\end{abstract}

\section{Introduction}

Emission of $\mathrm{CO}_{2}$ has become a serious concern due to increased global warming. Capture of $\mathrm{CO}_{2}$ from power plant flue gas, a mixture composed mainly of water-saturated $\mathrm{N}_{2}$ with smaller amounts of $\mathrm{O}_{2}$ and other species, is highly important. Effective separation technologies applied in power plants can decrease the total $\mathrm{CO}_{2}$ emission up to $40 \%$ [1]. Compared to traditional separation technologies, membrane-based gas separation offers low cost, energy efficiency, and relatively small ecological footprint [2]. Therefore, it is preferred for $\mathrm{CO}_{2} / \mathrm{N}_{2}$ separations in power plants. Polymer membranes have been widely used for this gas separation. Unfortunately, the main disadvantage of polymer membranes is the trade-off between gas permeability and selectivity [3]. Polymer membranes' selectivities tend to decrease as their permeabilities increase. For an efficient and economic gas separation process, both high gas selectivity and high gas permeability are required. High gas selectivity provides high purity and high gas permeability decreases the required surface area of the membrane and hence the capital cost. In order to overcome the trade-off of the polymer membranes, mixed matrix membranes (MMMs) are fabricated.
MMMs are heterogeneous membranes in which nanoporous materials such as zeolites [4], carbon nanotubes [5], zeolitic imidazolate frameworks (ZIFs) [6, 7], and carbon molecular sieves [8] are incorporated as filler particles into polymer membranes. A series of hybrid inorganic-organic membranes based on polymers and various organosilica structures was also synthesized [9]. MMMs combining two different kinds of porous fillers, a MOF and a zeolite, in a polymer matrix were also synthesized and tested for gas separations [10].

In this way, the advantages of nanoporous filler particles such as high gas permeability and high gas selectivity can be combined with the advantages of polymers such as easy processability and low cost [11]. MMMs can be fabricated on large scales with relatively minor adaptation of existing commercial technology developed for polymer membranes. If the appropriate fillers are chosen, both the selectivity and permeability of the polymer membrane can be improved. Among MMM fillers, MOFs are relatively new members of crystalline nanoporous materials [12-16]. MOFs are composed of metal complexes that are linked by organic ligands to create highly porous frameworks [17]. They have fascinating physical and chemical properties, very large surface 
areas $\left(500-6000 \mathrm{~m}^{2} / \mathrm{g}\right)$, high pore volumes $\left(1-4 \mathrm{~cm}^{3} / \mathrm{g}\right)$, wide range of pore sizes from micro- to mesoscale (1-98 $\AA$ ), and reasonable thermal and mechanical stabilities. Physical and chemical properties of MOFs can be tuned during synthesis and this controllable synthesis leads to a large diversity of materials with various structural properties and functionalities [18].

Incorporation of MOFs into polymers to improve the gas selectivity and permeability of the membrane has been recently investigated by several experimental and computational studies in the literature. We recently reviewed both the experimental and computational studies on MOF-based MMMs [19]. Several of these studies focused on $\mathrm{CO}_{2} / \mathrm{N}_{2}$ separations: Car et al. [20] studied the $\mathrm{CO}_{2} / \mathrm{N}_{2}$ selectivities of four different MMMs composed of CuBTC and Mn$(\mathrm{HCOO})_{2}$ as filler particles incorporated into polydimethylsiloxane (PDMS) and polysulfone (PSf) polymers. They obtained slight improvements in $\mathrm{CO}_{2}$ selectivity over $\mathrm{N}_{2}$. Perez and coworkers [21] incorporated MOF-5 into Matrimid and showed that the permeabilities increased to $124 \%$ for $\mathrm{CO}_{2}$ and $108 \%$ for $\mathrm{N}_{2}$ while selectivity remains almost the same as the pure polymer. Basu et al. [22] synthesized CuBTC/Matrimid and CuBTC/Matrimid/PSf MMMs and investigated mixed-gas permeation properties for $\mathrm{CO}_{2} / \mathrm{N}_{2}$. They observed increases in both $\mathrm{CO}_{2}$ permeability and $\mathrm{CO}_{2} / \mathrm{N}_{2}$ selectivity. The same group [23] also incorporated CuBTC, ZIF-8, and MIL-53(Al) into Matrimid and these MMMs showed higher $\mathrm{CO}_{2} / \mathrm{N}_{2}$ selectivity and higher $\mathrm{CO}_{2}$ permeability than unfilled Matrimid. Bae and Long [13] incorporated $\mathrm{Mg}_{2}$ (dobdc) into PDMS, cross-linked polyethylene oxide (XLPEO), and polyimide (6FDA-TMPDA). While the $\mathrm{CO}_{2}$ permeabilities of $\mathrm{Mg}_{2}$ (dobdc)/PDMS and $\mathrm{Mg}_{2}$ (dobdc)/XLPEO membranes decreased, the $\mathrm{CO}_{2} / \mathrm{N}_{2}$ selectivities were reported to slightly increase. Duan et al. [24] synthesized CuBTC/Ultem MMM with CuBTC and showed that the $\mathrm{CO}_{2}$ permeability is increased up to 2.6 times while the $\mathrm{CO}_{2} / \mathrm{N}_{2}$ selectivity is almost unchanged. Kim et al. [25] investigated $\mathrm{Cu}-\mathrm{MOF}$ as filler particle in polymer membranes, amorphous poly(2-ethyl-2-oxazoline), and semicrystalline poly(amide-6-b-ethylene oxide) and reported that ideal $\mathrm{CO}_{2} / \mathrm{N}_{2}$ selectivity of polymer membranes significantly increases with the addition of MOF particles.

As can be seen from the results of these experimental studies, MOF fillers can improve the gas separation performances of polymers. MOF-based MMMs can exhibit higher $\mathrm{CO}_{2} / \mathrm{N}_{2}$ selectivity and/or higher $\mathrm{CO}_{2}$ permeability than the pure polymer membranes. There are thousands of available MOFs that can be used as filler particles in polymer membranes. This high number of materials represents both opportunity and challenge to select the correct MOF/polymer combinations for MMM fabrications. It is not possible to synthesize all the possible MOF/polymer MMMs and report their gas separation performances using purely experimental manners. Computational studies that can accurately predict the selectivity and permeability of MOF-based MMMs are highly useful to efficiently screen large numbers of MOFs prior to experiments. In this way, experimental efforts, time, and resources can be directed to the most promising MOF fillers among many possible candidates. We recently developed a computational approach that combines atomically detailed simulations with continuum modeling to assess gas separation performances of MOF-based MMMs [26]. The accuracy of this approach was validated by comparing the predictions of our method with the available experimental gas permeability measurements of fabricated MOF-based MMMs such as IRMOF-1/Matrimid, CuBTC/PSf, and CuBTC/PDMS [27]. This method was then used to estimate the potential of new MOF-based MMMs in $\mathrm{CO}_{2} / \mathrm{CH}_{4}$ and $\mathrm{CH}_{4} / \mathrm{H}_{2}$ separations [27, 28]. We recently studied MMMs in which ZIFs [29] and porous coordination networks, PCNs [30], were used as fillers in polymers for $\mathrm{CO}_{2} / \mathrm{N}_{2}$ separations. 80 ZIF-based and 200 PCN-based MMMs were examined using molecular simulations and our results showed that a large number of ZIF- and PCN-filled MMMs have higher $\mathrm{CO}_{2}$ permeability and higher $\mathrm{CO}_{2} / \mathrm{N}_{2}$ selectivity than the pure polymers.

In this work, we expanded the number of studied MOFs significantly and considered 700 different MOF-based MMMs composed of $70 \mathrm{MOF}$ and 10 polymers for $\mathrm{CO}_{2} / \mathrm{N}_{2}$ separation. We first used atomically detailed simulations to calculate adsorption and diffusion of $\mathrm{CO}_{2}$ and $\mathrm{N}_{2}$ gases in MOFs. Using the gas adsorption and diffusion data, $\mathrm{CO}_{2} / \mathrm{N}_{2}$ selectivity and $\mathrm{CO}_{2}$ permeability of MOFs were computed to provide the first information about the separation potential of these materials. Relations between adsorption selectivity, diffusion selectivity, and permeation selectivity of MOFs were discussed. We then predicted the $\mathrm{CO}_{2} / \mathrm{N}_{2}$ selectivity and $\mathrm{CO}_{2}$ permeability of MOF-based MMMs and categorized the MOFs based on their effects on the separation performance of polymers. Our results showed that atomically detailed simulations can be used to select the appropriate MOF filler particles for polymers that will yield MMMs with extraordinary $\mathrm{CO}_{2} / \mathrm{N}_{2}$ separation properties.

\section{Computational Details}

2.1. MOFs and Polymers. In this work, 70 different MOFs and 10 different polymers were studied as components of 700 different MMMs. This is the largest number of MOFbased MMMs for which computational screening is done to date. Crystal structures of the selected MOF materials were taken from the Cambridge Crystallographic Data Centre (CCDC) [31]. The CCDC names and structural properties such as pore limiting diameter (PLD), largest cavity diameter (LCD), pore volume, and surface area of the MOFs are given in Table S1 in Supplementary Material available online at http://dx.doi.org/10.1155/2016/6482628. These structural properties were computed using Zeo++ [32] software. For surface area (pore volume) calculations, the number of trials was set to 2000 (50000) and probe size was set to 1.86 (zero) A. For two MOFs, PODKUQ and QIFLOI, calculations were performed using Sarkisov and Harrison's algorithm, Poreblazer [33]. We used universal force field (UFF) [34] for Poreblazer algorithm. Parameters such as He atom's sigma, He atom's epsilon, $\mathrm{N}$ atom's sigma, temperature, cut-off distance, and number of trials were set to $2.58 \AA, 10.22 \mathrm{~K}, 3.314 \AA$, $298 \mathrm{~K}, 12.8 \AA$, and 500, respectively. The largest anticipated pore diameter was set to $20 \AA$ and the size of the bin was set to $0.25 \AA$. 
As polymers, Ultem, Matrimid, polyimide (thianthrene2,3,7,8-tetracarboxylic dianhydride-5,5,10,10-tetraoxide (TADATO), 3,3',4,4' -diphenylsulfonyltetracarboxylic dianhydride (DSDA), and 3,7-diamino-2,8(6)-dimethyldibenzothiophene sulfone (DDBT)), 6FDA-2,2-bis(3,4-carboxyphenyl) hexafluoropropane dianhydride-diaminomesitylene (DAM) (6FDADAM), poly(bis(2-(2-methoxyethoxy)ethoxy)phosphazene) (MEEP), polymers of intrinsic microporosity (PIM-1 and PIM-7), modified PDMS, poly(trimethylgermylpropyne) (PTMGP), and poly(trimethylsilypropyne) (PTMSP) were studied [3]. Ultem, Matrimid, 6FDA-DAM, and modified PDMS were selected because they are widely used in experimental studies of MMMs. MEEP, PIM-1, PIM-7, PTMGP, and PTMSP were selected because they are close to Robeson's upper bound. If the appropriate MOF fillers are incorporated, their $\mathrm{CO}_{2}$ selectivities and $\mathrm{CO}_{2}$ permeabilities can be enhanced to exceed the upper bound. The polymers that we considered in this work represent a wide range of $\mathrm{CO}_{2}$ selectivity and permeability. For example, Ultem, Matrimid, and polyimide have low $\mathrm{CO}_{2}$ permeabilities (1.4, 9, and 45 Barrers, resp.) but high $\mathrm{CO}_{2} / \mathrm{N}_{2}$ selectivities (25, 36, and 35.4, resp.). MEEP, 6FDA-DAM, PIM-7, modified PDMS, and PIM-1 have high $\mathrm{CO}_{2}$ permeabilities (250, 842.4, 1100,2000 , and 2300, resp.). PTMGP and PTMSP have the highest $\mathrm{CO}_{2}$ permeabilities (14000 and 29000 Barrers, resp.) but their $\mathrm{CO}_{2} / \mathrm{N}_{2}$ selectivities are low (14 and 10.7, resp.). Complete data for $\mathrm{CO}_{2}$ permeabilities, $\mathrm{N}_{2}$ permeabilities, and $\mathrm{CO}_{2} / \mathrm{N}_{2}$ selectivities of polymers are given in Table S2 in Supplementary Material.

2.2. Atomically Detailed Simulations. In order to calculate gas permeabilities of MOF-based MMMs, we need to know gas permeabilities of polymers and MOFs. Gas permeabilities of polymers were taken from the literature because there is a large amount of experimental studies related to polymers and their gas permeabilities [3]. Gas permeabilities of MOFs were computed in this work using atomically detailed simulations. Grand Canonical Monte Carlo (GCMC) and equilibrium molecular dynamics (EMD) simulations were used to compute gas adsorption and gas diffusion in MOFs, respectively [35]. Adsorption and diffusion data were then used to compute the gas permeabilities.

In GCMC and EMD simulations, UFF and Dreiding [36] force fields were used for MOFs in order to define the Lennard-Jones (LJ) potential parameters of the framework atoms. These force fields were selected based on the results of previous simulation studies that show a good agreement with the available experimental gas uptake data of MOFs [37]. The force fields used for each MOF together with the CCDC names of the MOFs are given in Table S3. The $\mathrm{CO}_{2}$ molecule was modeled as three-site rigid molecule with LJ 126 potential; location of partial point charges was set as center of each side [38]. The $\mathrm{N}_{2}$ molecule was modeled as three-site molecule, two sites were located at the $\mathrm{N}$ atoms, and third site was located at the center of the mass with partial point charges [39]. The LJ cross-interaction parameters for gas-gas and gas-MOF were calculated using Lorenz-Berthelot mixing rules. Electrostatic interactions were taken into consideration using the Coulomb potential. In order to compute the electrostatic interactions between gas molecules and MOFs, partial charges were assigned to MOF atoms using extended charge equilibration method (EQeq) [40]. The cut-off distance for truncation of dispersion and electrostatic interactions was set to $13 \AA$ and $25 \AA$, respectively.

GCMC simulations were performed to compute singlecomponent adsorption isotherms of $\mathrm{CO}_{2}$ and $\mathrm{N}_{2}$ in MOFs. The adsorbed amount of each gas was calculated by specifying the pressure and temperature. These simulations were performed at pressures of 2 bar and $10^{-6}$ bar at $298 \mathrm{~K}$ since most MMMs are experimentally tested for a feed pressure of 2 bar and permeate pressure of vacuum at room temperature. All simulations were done at room temperature, $298 \mathrm{~K}$. Four different movement types were used in simulations, translation, rotation, insertion, and deletion of a molecule. Periodic boundary conditions were applied to simulate the bulk phase. A simulation box of $2 \times 2 \times 2$ crystallographic unit cells was used. The number of steps was set to $1.5 \times 10^{7}$ for equilibration and $1.5 \times 10^{7}$ for production in simulations.

EMD simulations were performed to calculate the corrected diffusivity $\left(D_{0}\right)$ of each gas. These simulations were done at average of feed and permeate pressure loadings that were obtained from the GCMC simulations. In each EMD simulation, 20 independent trajectories with $16 \mathrm{~ns}$ length were collected. Corrected diffusivities of gases were calculated in three directions and average diffusivity was reported. If diffusion was in one (two) direction(s), only that diffusivity (average diffusivity of these directions) was used. The Nose-Hoover thermostat algorithm was applied in NVT ensemble (constant number of molecules, constant volume, and constant temperature) [35]. The simulation volume was increased up to $6 \times 6 \times 6$ crystallographic unit cells to ensure that it contains enough gas molecules at the lowest loadings to increase the statistical accuracy of the simulations.

Transport diffusivity $\left(D_{\mathrm{t}}\right)$ was calculated by multiplying the corrected diffusivity $\left(D_{0}\right)$ obtained from EMD simulations with the thermodynamic correction factor [41], the partial derivative relating adsorbate concentration, $c$, and the bulk phase fugacity, $f$. If the single-component adsorption isotherm of the gas is known, the thermodynamic correction factor can be fully defined as follows:

$$
D_{\mathrm{t}}(c)=D_{0}(c) \cdot \frac{\partial \ln f}{\partial \ln c} .
$$

Steady-state gas fluxes $(J)$ through a MOF were then calculated based on Fick's law [41],

$$
J=-D_{\mathrm{t}}(c) \cdot \nabla c
$$

where $\nabla c$ is the concentration gradient of the adsorbed species based on the difference between feed and permeate pressures of the membrane. Gas flux in a MOF was then converted to gas permeability $\left(P_{\mathrm{MOF}}\right)$, using the pressure drop $(\Delta P)$ and membrane thickness $(L)$, as shown in the following:

$$
P_{\mathrm{MOF}}=\frac{J}{\Delta P / L}
$$


Permeation selectivity (also referred to as membrane selectivity) of a $\operatorname{MOF}(S)$ was calculated from the ratio of gas permeability of two components:

$$
S_{\mathrm{CO}_{2} / \mathrm{N}_{2}}=\frac{P_{\mathrm{CO}_{2}}}{P_{\mathrm{N}_{2}}} .
$$

2.3. Calculating Gas Permeability of MMMs. Gas permeabilities of MMMs were calculated using the well-known Maxwell model [42]. Erucar and Keskin [28] previously compared several theoretical permeation models, including Maxwell, modified Maxwell, Bruggeman, Lewis-Nielson, Pal, Felske, and modified Felske and showed that the Maxwell model is the best predicting model among the ones considering ideal morphology. In addition to these, we recently used the Maxwell model to predict $\mathrm{CO}_{2}$ and $\mathrm{N}_{2}$ permeabilities of MOF-based MMMs with a MOF volume fraction of 0.3 and showed the good agreement between simulation results and experiments for gas permeabilities of MOF-based MMMs [30]. These results suggested that it is reasonable to use the Maxwell model for estimating separation performance of new MOF-based MMMs for which experimental gas permeability data are not available. The Maxwell model predicts a MMM's gas permeability $(P)$ based on the polymer's gas permeability $\left(P_{\mathrm{p}}\right)$, filler particle's permeability $\left(P_{\mathrm{f}}\right)$, and the volume fraction of the filler particle within the polymer matrix $(\phi)$ as follows:

$$
\begin{aligned}
P & =P_{\mathrm{p}}\left[\frac{2(1-\phi)+(1+2 \phi) \lambda_{\mathrm{fp}}}{(2+\phi)+(1-\phi) \lambda_{\mathrm{fp}}}\right], \\
\lambda_{\mathrm{fp}} & =\frac{P_{\mathrm{f}}}{P_{\mathrm{p}}} .
\end{aligned}
$$

We used the MOF's permeability, $P_{\mathrm{MOF}}$, calculated from (3) as the filler particle's permeability $\left(P_{\mathrm{f}}\right)$ in $(6)$. Gas selectivities of MMMs were computed as the ratio of gas permeabilities obtained from the Maxwell model similar to (4).

\section{Results and Discussion}

3.1. Permeability and Selectivity of MOFs. Before analyzing the results for MOF-based MMMs, we first examined the $\mathrm{CO}_{2} / \mathrm{N}_{2}$ separation performances of MOFs. Predicted $\mathrm{CO}_{2}$ permeabilities, $\mathrm{N}_{2}$ permeabilities, and $\mathrm{CO}_{2} / \mathrm{N}_{2}$ selectivities of MOFs are given in Table S4 in Supplementary Material. Figure 1 shows the $\mathrm{CO}_{2} / \mathrm{N}_{2}$ selectivities and $\mathrm{CO}_{2}$ permeabilities of 70 different MOFs calculated from atomically detailed simulations. We also showed the selectivity and permeability data for 10 different polymers that we considered in this work together with Robeson's upper bound established for $\mathrm{CO}_{2} / \mathrm{N}_{2}$ separation. Membrane materials that can exceed this upper bound are considered to be highly promising. The first observation from Figure 1 is that there are several MOFs that can exceed Robeson's upper bound. 27 of the $70 \mathrm{MOF}$ are located above the upper bound. Most of these MOFs have generally similar or lower $\mathrm{CO}_{2} / \mathrm{N}_{2}$ selectivities than the polymers but significantly higher $\mathrm{CO}_{2}$ permeabilities. MOFs, HAJKOU,
LARVIL, and NUJCIE exhibit high $\mathrm{CO}_{2} / \mathrm{N}_{2}$ selectivities, 59, 54 , and 49 , respectively, and their $\mathrm{CO}_{2}$ permeabilities are $7.5 \times$ $10^{5}, 7 \times 10^{6}$, and $2.6 \times 10^{5}$ Barrers. These values are higher than the selectivities and permeabilities of the polymers. Therefore, it is expected that if these three MOFs are used as filler particles in the polymers, they can significantly enhance both the selectivity and permeability of the polymer membranes. IDIWOH has the highest $\mathrm{CO}_{2}$ permeability among all MOFs we considered, $\sim 10^{7}$ Barrers. However, the $\mathrm{CO}_{2} / \mathrm{N}_{2}$ selectivity of this MOF (6) is lower than that of polymers. If IDIWOH is incorporated into polymers, we expect an increase in the $\mathrm{CO}_{2}$ permeabilities of the polymers but decrease or no change in their selectivities.

One important observation from Figure 1 is that almost all MOFs that we considered in this work have higher $\mathrm{CO}_{2}$ permeabilities than the polymers. The $\mathrm{CO}_{2}$ permeabilities of polymers are in the range of $1-10^{4}$ Barrers whereas MOFs exhibit $\mathrm{CO}_{2}$ permeabilities of $10^{4}-10^{7}$ Barrers. These high permeabilities can be attributed to the large pore volumes of MOFs. We showed the calculated surface areas and pore volumes of all 70 MOFs in Figure S1. Surface areas of MOFs vary between 90 and $5210 \mathrm{~m}^{2} / \mathrm{g}$ and pore volumes are in the range of $0.1-3.1 \mathrm{~cm}^{3} / \mathrm{g}$, which explains the high gas permeabilities of MOFs compared to polymers. As can be seen from Figure S1, the computed surface area in general closely correlates with the pore volume. As the pore volumes increase, surface areas also increase. The MOFs that we identified to be highly promising for $\mathrm{CO}_{2} / \mathrm{N}_{2}$ separations in Figure 1, NUJCIE, LARVIL, and HAJKOU have low surface areas $\left(175 \mathrm{~m}^{2} / \mathrm{g}, 350 \mathrm{~m}^{2} / \mathrm{g}\right.$, and $890 \mathrm{~m}^{2} / \mathrm{g}$, resp. $)$ and low pore volumes $\left(0.28 \mathrm{~cm}^{3} / \mathrm{g}, 0.24 \mathrm{~cm}^{3} / \mathrm{g}\right.$, and $0.39 \mathrm{~cm}^{3} / \mathrm{g}$, resp.). As previously discussed by Watanabe and Sholl [43], high surface areas and pore volumes are generally preferred for materials used for adsorbent applications but are not critical for membrane materials. Overall, Figure 1 suggests that there are several promising MOFs with high $\mathrm{CO}_{2} / \mathrm{N}_{2}$ selectivities and high $\mathrm{CO}_{2}$ permeabilities and these MOFs can be promising fillers for MMMs to enhance polymers' separation performances.

In order to better assess gas separation performances of MOFs, we examined adsorption and diffusion selectivities of MOFs separately. Figure 2 shows adsorption, diffusion, and permeation (membrane) selectivity of MOFs as a function of their PLDs. Adsorption selectivities were computed as the ratio of adsorbed amount of $\mathrm{CO}_{2}$ to $\mathrm{N}_{2}$ at the average loadings of feed and permeate pressures. All MOFs are $\mathrm{CO}_{2}$ selective in adsorption regardless of their pore sizes as shown in Figure 2(a). This is expected since $\mathrm{CO}_{2}$ molecules have stronger energetic interactions with the MOF atoms compared to $\mathrm{N}_{2}$ molecules as a result of higher quadrupole moment of $\mathrm{CO}_{2}$. Strong adsorption of $\mathrm{CO}_{2}$ molecules over weak adsorption of $\mathrm{N}_{2}$ molecules gives rise to the $\mathrm{CO}_{2}$ selective trend in adsorption. Adsorption selectivities of MOFs are moderate and close to each other in the range of 3-20. The best performing MOFs in adsorption are LECQEQ, EDUSUR, and LARVIL with adsorption selectivities of 17,20 , and 20.3, respectively. The MOFs that we identified to be highly promising for $\mathrm{CO}_{2} / \mathrm{N}_{2}$ separation based on permeation selectivity results, HAJKOU, 


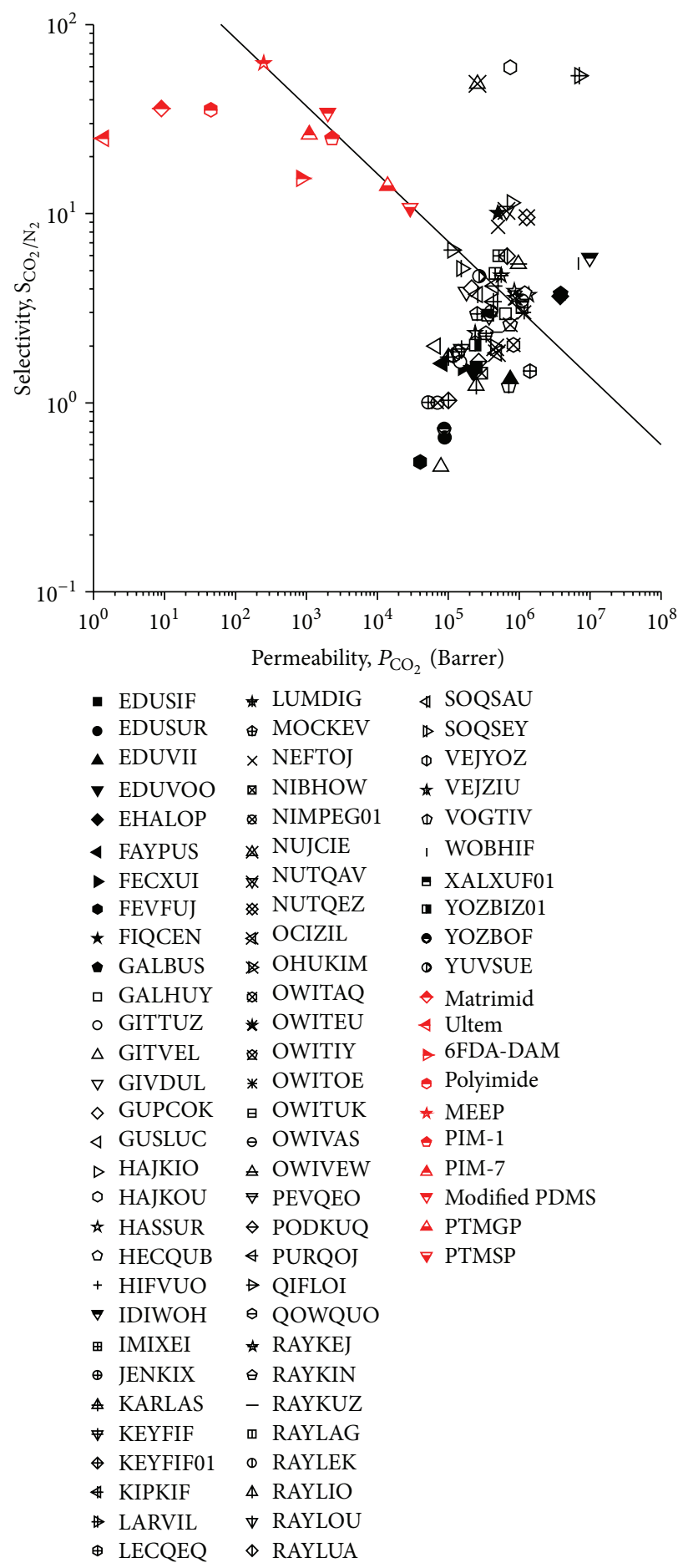

Figure 1: Predicted $\mathrm{CO}_{2} / \mathrm{N}_{2}$ selectivities and $\mathrm{CO}_{2}$ permeabilities of 70 MOFs considered in this work. Experimental data of polymer membranes is taken from the literature [3]. The line represents Robeson's upper bound for the $\mathrm{CO}_{2} / \mathrm{N}_{2}$ separation.

NUJCIE, and LARVIL, have adsorption selectivities of 4, 15 , and 20.3, respectively. This result suggests that the most promising membrane candidates for selective $\mathrm{CO}_{2}$ separation are not necessarily the ones with the highest $\mathrm{CO}_{2}$ adsorption selectivities.
Figure 2(b) shows diffusion selectivities of MOFs calculated as the ratio of corrected diffusivity of $\mathrm{CO}_{2}$ over $\mathrm{N}_{2}$ obtained from the EMD simulations. It is important to note that both $\mathrm{CO}_{2}$ and $\mathrm{N}_{2}$ diffusivities were greater than $10^{-8} \mathrm{~cm}^{2}$ / $s$ in all MOFs we studied since gas diffusion can be readily 


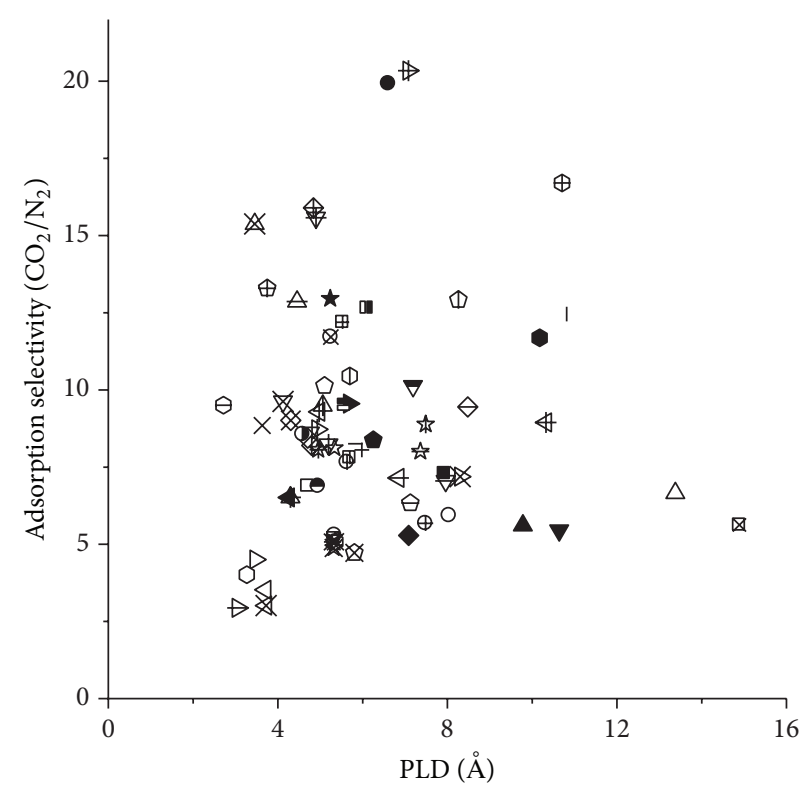

(a)

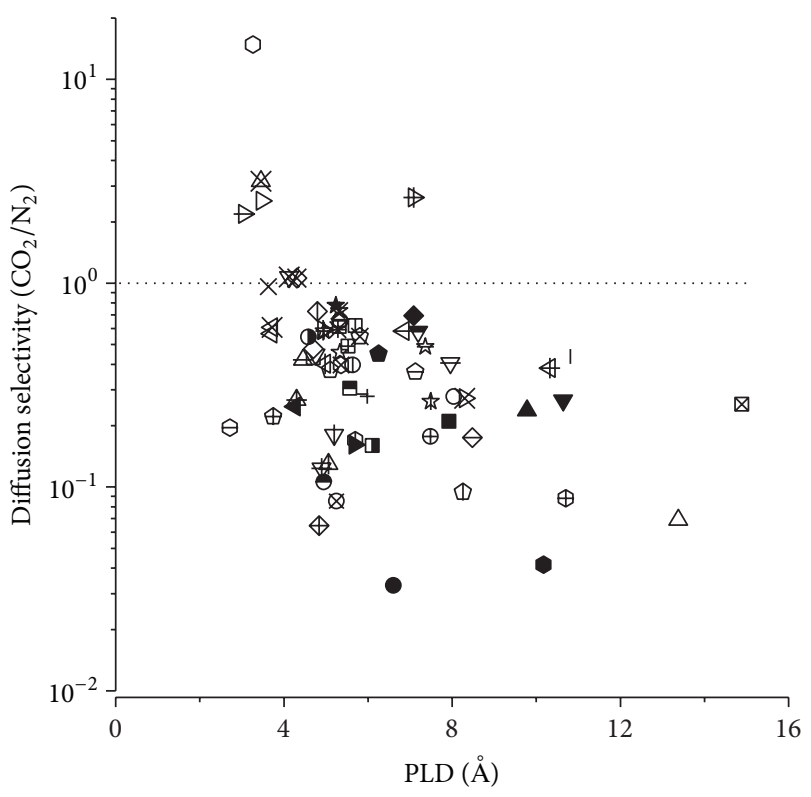

(b)

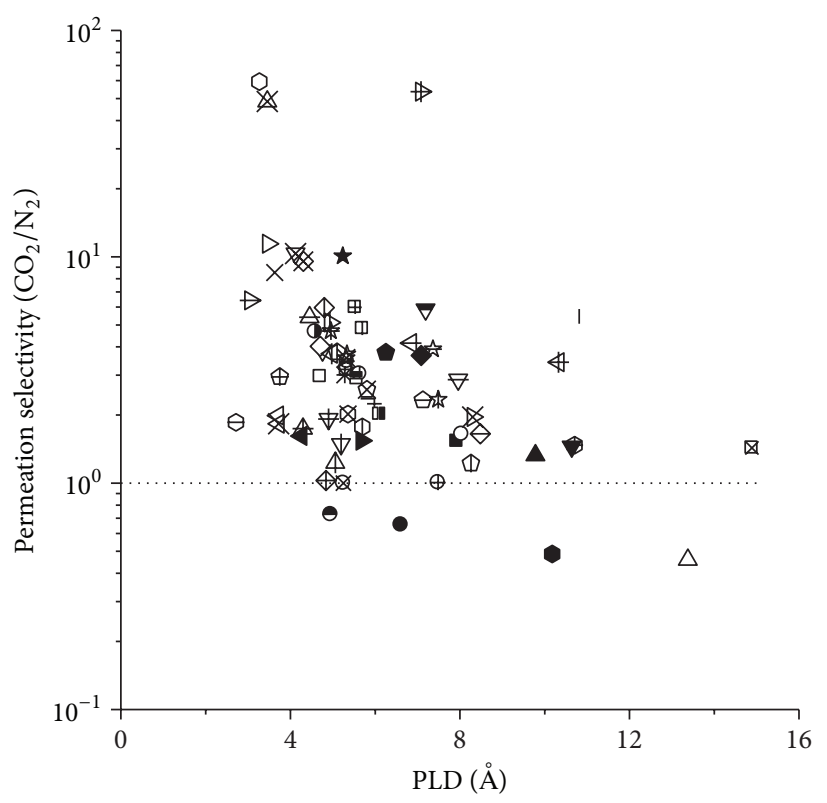

(c)

FIgURE 2: (a) Adsorption selectivity, (b) diffusion selectivity, and (c) permeation selectivity of MOFs as a function of their PLDs (pore limiting diameters). Legend is the same as Figure 1. The dotted lines in (b) and (c) represent the selectivity of 1.

characterized with EMD simulations above this limit. One important observation from Figure 2(b) is that there is no correlation between diffusion selectivity of MOFs and their PLDs. There are many MOFs having similar PLDs but different diffusion selectivities. A significant amount of MOFs, 63 out of 70, has diffusion selectivity less than 1 for $\mathrm{CO}_{2}$ over $\mathrm{N}_{2}$. In other words, these MOFs are $\mathrm{N}_{2}$ selective in diffusion. This is an expected result since $\mathrm{N}_{2}$ molecules are lighter than the $\mathrm{CO}_{2}$ molecules leading to faster diffusion of $\mathrm{N}_{2}$ compared to $\mathrm{CO}_{2}$. Furthermore, $\mathrm{CO}_{2}$ molecules are strongly adsorbed in MOFs as shown in Figure 2(a) and slow diffusion of the strongly adsorbed components is a common observation. Interestingly, there are five MOFs that favor $\mathrm{CO}_{2}$ in diffusion. These MOFs are QIFLOI, HAJKIO, LARVIL, NUJCIE, and HAJKOU which have diffusion selectivities of $2.2,2.5,2.6$, 3.2, and 14.8, respectively, for $\mathrm{CO}_{2}$ over $\mathrm{N}_{2}$. Three of these MOFs, LARVIL, NUJCIE, and HAJKOU, were identified to be highly promising materials for $\mathrm{CO}_{2} / \mathrm{N}_{2}$ separations due to their high permeation selectivities in Figure 1. The reason for their high permeation selectivities is that both adsorption and diffusion favor the same component, $\mathrm{CO}_{2}$, in these MOFs. Therefore, these three MOFs are highly $\mathrm{CO}_{2}$ selective 
materials. Although QIFLOI and $\mathrm{HAJKIO}$ are $\mathrm{CO}_{2}$ selective in diffusion, their adsorption selectivities for $\mathrm{CO}_{2}$ are low (3 and 4.5) compared to other MOFs; therefore, they are not as selective for $\mathrm{CO}_{2}$ as the other three MOF materials in permeation. Finally, there are several MOFs with diffusion selectivities close to 1 , suggesting that diffusion rates of $\mathrm{CO}_{2}$ and $\mathrm{N}_{2}$ are similar in the pores of these materials. As a result, permeation selectivities of these materials are determined by their adsorption selectivities.

Permeation (membrane) selectivities of MOFs are shown in Figure 2(c). Except four, all MOFs are $\mathrm{CO}_{2}$ selective membranes. The $\mathrm{CO}_{2} / \mathrm{N}_{2}$ selectivities are in the range of 0.45-59.5. The $\mathrm{CO}_{2} / \mathrm{N}_{2}$ selectivities of FEVFUJ, GITVEL, EDUSUR, and YOZBOF are $0.5,0.5,0.7$, and 0.7 , respectively, which show that they are $\mathrm{N}_{2}$ selective. Adsorption favors $\mathrm{CO}_{2}$ in these MOFs with selectivities of $\sim 12,7,20$, and 7 , but diffusion very strongly favors $\mathrm{N}_{2}$ over $\mathrm{CO}_{2}$ with selectivities of $24,15,30$, and 9, respectively. Diffusion selectivities for $\mathrm{N}_{2}$ dominate the adsorption selectivities for $\mathrm{CO}_{2}$ and as a result these MOFs become $\mathrm{N}_{2}$ selective membranes. FEVFUJ, GITVEL, EDUSUR, and YOZBOF can be promising adsorbent candidates for selective separation of $\mathrm{CO}_{2}$ from $\mathrm{N}_{2}$ and at the same time they are promising membrane materials for selective separation of $\mathrm{N}_{2}$ from $\mathrm{CO}_{2}$. For example, EDUSUR exhibits one of the highest adsorption selectivities for $\mathrm{CO}_{2}$, 20, as shown in Figure 2(a) but when the kinetic properties of gases are considered, EDUSUR becomes weakly $\mathrm{N}_{2}$ selective membrane as shown in Figure 2(c). This example signifies the importance of diffusion selectivity in governing a material's membrane selectivity. Overall, analysis of adsorption, diffusion and permeation selectivities of MOFs obtained from atomically detailed simulations can be summarized as follows. (i) Adsorption selectivity favors $\mathrm{CO}_{2}$ in all MOFs. (ii) If the diffusion selectivity also favors $\mathrm{CO}_{2}$, then these MOFs become highly $\mathrm{CO}_{2}$ selective in permeation. (iii) If the diffusion selectivity weakly favors $\mathrm{N}_{2}$, then these MOFs become weakly $\mathrm{CO}_{2}$ selective in permeation. (iv) If the diffusion selectivity strongly favors $\mathrm{N}_{2}$, then these MOFs become $\mathrm{N}_{2}$ selective in permeation.

3.2. Permeability and Selectivity of MOF-Based MMMs. In our recent work, we compared the $\mathrm{CO}_{2}$ and $\mathrm{N}_{2}$ permeability predictions of our atomically detailed simulations with the experimentally measured ones for various MOF- and ZIFbased MMMs [30]. We collected 98 experimental data points from the literature for $\mathrm{CO}_{2}$ and $\mathrm{N}_{2}$ permeability of 15 different types of MOF- and ZIF-based MMMs and showed that predictions of the Maxwell model are in good agreement with the experimental measurements of $\mathrm{CO}_{2}$ and $\mathrm{N}_{2}$ permeability. This good agreement validated the accuracy of our computational methodology to estimate separation performances of new MOF-based MMMs for which experimental gas permeability data are not available. In this work, we used the same computational approach to predict $\mathrm{CO}_{2}$ and $\mathrm{N}_{2}$ permeabilities and $\mathrm{CO}_{2} / \mathrm{N}_{2}$ selectivities of 700 different MOF-based MMMs which have not been fabricated to date. Calculated gas permeability and selectivity data for all MOFbased MMMs are reported in Tables S5-S14.

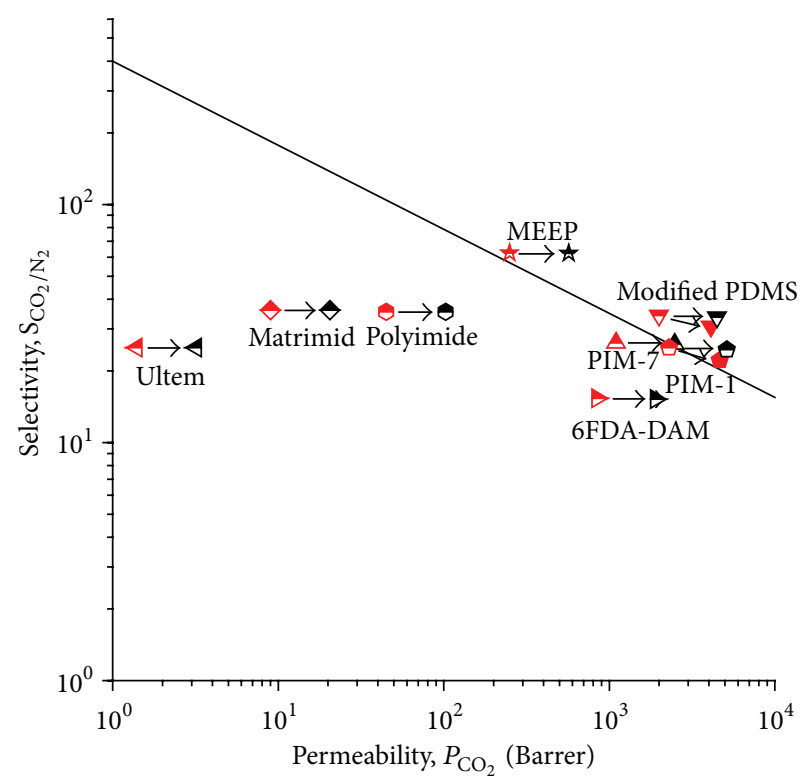

FIgure 3: Predicted $\mathrm{CO}_{2} / \mathrm{N}_{2}$ selectivities and $\mathrm{CO}_{2}$ permeabilities of 560 different MOF-based MMMs composed of Ultem, Matrimid and polyimide, 6FDA-DAM, MEEP, PIM-7, PIM-1, and modified PDMS polymers. The line represents Robeson's upper bound for the $\mathrm{CO}_{2} / \mathrm{N}_{2}$ separation. Half full red indicates pure polymers, half full black indicates the MOF/polymer MMMs, and full red indicates FEVFUJ/polymer MMM.

Figure 3 shows predicted $\mathrm{CO}_{2} / \mathrm{N}_{2}$ selectivity and $\mathrm{CO}_{2}$ permeability of 560 different MMMs composed of Ultem, Matrimid, polyimide, MEEP, modified PDMS, PIM-1, PIM-7, and 6FDA-DAM polymers. The volume fraction of the MOF fillers in MMMs was set to 0.3. Predicted gas permeabilities of different MOF-based MMMs composed of 6FDA-DAM, Ultem, PIM-7, polyimide, Matrimid, and MEEP are almost the same; therefore a single symbol was used to represent different MOF-based MMMs of these polymers. In other words, the identity of the MOF used as filler particle does not affect the performance of MMMs composed of these six polymers. Ultem, Matrimid, polyimide, and 6FDA-DAM are below the upper bound due to their low $\mathrm{CO}_{2}$ permeabilities compared to other polymers. Results showed that adding MOFs as filler particles into these polymers increases the $\mathrm{CO}_{2}$ permeability of polymers since all the MOFs we studied have higher $\mathrm{CO}_{2}$ permeability than these polymers. For example, $\mathrm{CO}_{2}$ permeability increases from 1.4 to 3.2 Barrers for Ultembased MMMs, 9 to 21 Barrers for Matrimid-based MMMs, 45 to 102.8 Barrers for polyimide-based MMMs, and 842.4 to 1908.7 Barrers for 6FDA-DAM-based MMMs. On the other hand, there is almost no change in $\mathrm{CO}_{2} / \mathrm{N}_{2}$ selectivity of these polymers.

With a $\mathrm{CO}_{2} / \mathrm{N}_{2}$ selectivity of 26.2 and $\mathrm{CO}_{2}$ permeability of 1100 Barrers, PIM-7 is just below the upper bound. When MOFs are used as filler particles in this polymer, the MMM's permeability increases from 1100 to 2485.9 Barrers and as a result PIM-7 can exceed the upper bound. This is an important result showing that highly permeable MOFs can significantly improve the $\mathrm{CO}_{2}$ permeability of polymers and 


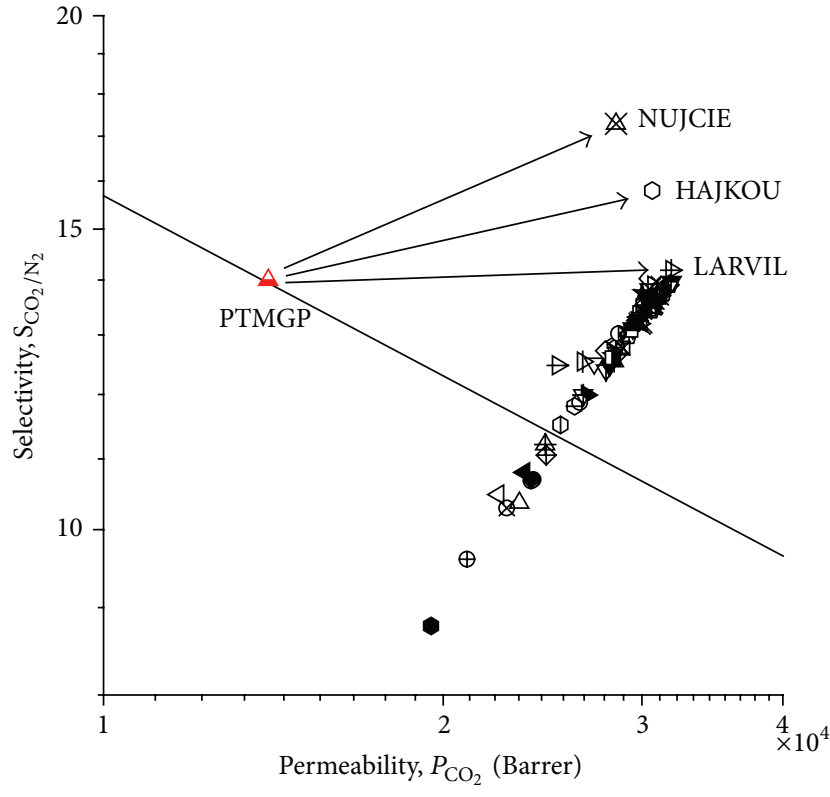

(a)

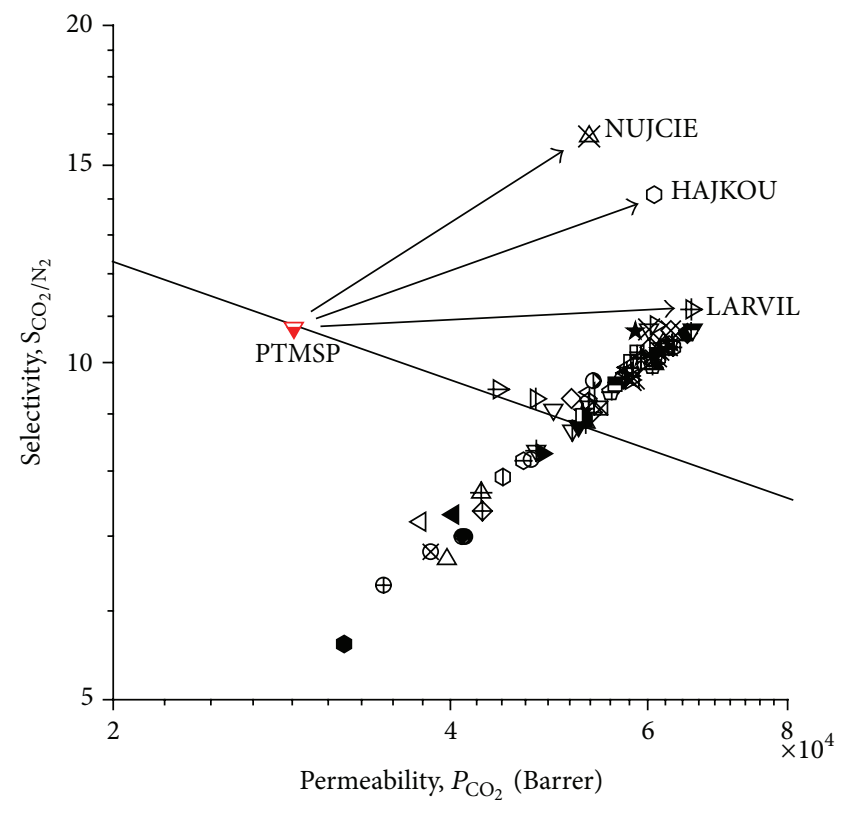

(b)

FIgURE 4: Predicted $\mathrm{CO}_{2} / \mathrm{N}_{2}$ selectivities and $\mathrm{CO}_{2}$ permeabilities of 70 different MOF-based MMMs composed of (a) PTMGP and (b) PTMSP polymers. Red symbols represent the pure polymer membranes and black symbols represent the MOF-based MMMs. Legend is the same as Figure 1.

carry them above the upper bound. MEEP polymer is on Robeson's upper bound and it easily exceeds the upper bound due to the improvement in $\mathrm{CO}_{2}$ permeability by addition of MOF fillers. The $\mathrm{CO}_{2}$ permeability of MEEP polymer increases from 250 to 570 Barrers with the incorporation of MOFs. No increase in the selectivity of MEEP was expected since it has the highest selectivity among all MOFs and polymers we considered in this work. The identity of the MOF used as filler affects the performance of MMMs composed of modified PDMS and PIM-1. These two polymers have significantly higher $\mathrm{CO}_{2}$ permeabilities than the other polymers, 2000 and 2300 Barrers, respectively. There is a single MOF, FEVFUJ, which adversely affects the selectivity of these two polymers. FEVFUJ is $\mathrm{N}_{2}$ selective MOF as shown in Figure 1. It has the lowest $\mathrm{CO}_{2}$ selectivity (0.5) and the lowest $\mathrm{CO}_{2}$ permeability (40500 Barrers) among all the MOFs we considered. If FEVFUJ is used as filler in modified PDMS and PIM-1, the $\mathrm{CO}_{2}$ permeabilities still increase but at the expense of decreasing $\mathrm{CO}_{2}$ selectivities as shown in Figure 3. For example, the $\mathrm{CO}_{2} / \mathrm{N}_{2}$ selectivity of modified PDMS (PIM1) decreases from 34.2 to 30.7 (25 to 22.2) while the $\mathrm{CO}_{2}$ permeability increases from 2000 to 4103.1 (2300 to 4650.5 ) Barrers. Incorporation of other MOFs into modified PDMS and PIM-1 gives similar results; permeabilities are enhanced while selectivities remain constant.

PTMGP and PTMSP are the two polymers located at the lower right end of Robeson's upper bound as shown in Figure 1. They have high $\mathrm{CO}_{2}$ permeabilities (14000 and 29000 Barrers, resp.), but low $\mathrm{CO}_{2} / \mathrm{N}_{2}$ selectivities (14 and 10.7 , resp.). The gas permeabilities of these two polymers are much closer to the gas permeabilities of MOFs compared to the other polymers. Because of this reason, MMMs composed of PTMGP and PTMSP exhibit significantly different separation performances based on the identity of the MOF used as fillers. Figure 4(a) shows predicted $\mathrm{CO}_{2} / \mathrm{N}_{2}$ selectivity and $\mathrm{CO}_{2}$ permeability of 70 different MOF/PTMGP MMMs. The effect of MOF fillers can be categorized into three: MOFs that increase both the $\mathrm{CO}_{2}$ permeability and $\mathrm{CO}_{2} / \mathrm{N}_{2}$ selectivity, MOFs that increase the permeability without changing the selectivity, and MOFs that increase the permeability at the expense of decreasing selectivity. We discuss each case in detail in the following.

(a) Only 3 MOFs, NUJCIE, HAJKOU, and LARVIL, can increase both the $\mathrm{CO}_{2}$ permeability and $\mathrm{CO}_{2} / \mathrm{N}_{2}$ selectivity of PTMGP. The selectivity of PTMGP increases from 14 to 17.3 and its permeability increases from 14000 to 28500 Barrers when NUJCIE is used as a filler particle. If HAJKOU is used to make a MMM, then the selectivity increases to 16 and permeability increases to 30650 Barrers. LARVIL also slightly increases the $\mathrm{CO}_{2}$ selectivity of PTMGP to 14.2 and significantly increases the $\mathrm{CO}_{2}$ permeability to 31850 Barrers. All three MMMs, NUJCIE/PTMGP, HAJKOU/PTMGP, and LARVIL/PTMGP, can exceed the upper bound established for $\mathrm{CO}_{2} / \mathrm{N}_{2}$ separation.

(b) Several MOFs (19 among 70) improve the $\mathrm{CO}_{2}$ permeability of PTMGP but they do not significantly affect its selectivity. All these MOFs carry PTMGP above the upper bound due to large increases in the $\mathrm{CO}_{2}$ permeability. The highest permeability observed for PTMGP-based MMMs is 31900 Barrers with IDIWOH filler while selectivity is constant at 14 . 
(c) A significant number of MOFs (48 among 70) increase the $\mathrm{CO}_{2}$ permeability of PTMGP but decrease its selectivity. The reason is that the $\mathrm{CO}_{2}$ permeabilities of these MOFs are similar to the PTMGP while their $\mathrm{CO}_{2} / \mathrm{N}_{2}$ selectivities are significantly lower than the polymer. As a result, the improvement in the $\mathrm{CO}_{2}$ permeability of polymers occurs at the expense of a reduction in the selectivity. For example, the $\mathrm{CO}_{2}$ permeability of PTMGP increases from 14000 to 19500 Barrers while its selectivity decreases from 14 to 8.8 with the addition of FEVFUJ filler into the polymer.

Figure 4(b) shows predicted $\mathrm{CO}_{2} / \mathrm{N}_{2}$ selectivity and $\mathrm{CO}_{2}$ permeability of 70 different MOF-based MMMs composed of PTMSP polymer. PTMSP-based MMMs show the same trend with PTMGP-based MMMs. NUJCIE, HAJKOU, and LARVIL are the MOFs that increase both permeability and selectivity of PTMSP. NUJCIE increases permeability (selectivity) from 29000 to 53200 Barrers (from 10.7 to 15.9), HAJKOU increases to 60800 Barrers (to 14.1), and LARVIL increases to 65650 Barrers (to 11.2). MMMs in which NUJCIE, HAJKOU, and LARVIL are used as fillers exceed the upper bound established for $\mathrm{CO}_{2} / \mathrm{N}_{2}$ separation. There are 17 MOFs which improve the $\mathrm{CO}_{2}$ permeability of PTMSP but do not significantly change the $\mathrm{CO}_{2}$ selectivity. For example, IDIWOH increases the $\mathrm{CO}_{2}$ permeability to 65800 Barrers but keeps the selectivity of MMM the same as that of pure polymer. Permeability increases upon addition of MOF fillers carry the PTMSP-based MMMs above the upper bound. Most of the MOFs studied (50 among 70) increased the $\mathrm{CO}_{2}$ permeability of PTMSP but decreased the $\mathrm{CO}_{2}$ selectivity due to the same reason as discussed for PTMGP.

We so far examined the widely studied polymers for $\mathrm{CO}_{2} /$ $\mathrm{N}_{2}$ separation. In fact, most of these polymers are located close to the upper bound and it is easy for these polymers to exceed the upper bound with the incorporation of highly permeable MOF fillers. We now turn to the hypothetical polymers to understand which polymers can reap the largest advantages when used in combination with MOFs. Figure 5 shows 6 hypothetical polymers that lie along Robeson's upper bound for $\mathrm{CO}_{2} / \mathrm{N}_{2}$ separation. By specifying the position of a polymer along the upper bound we defined the information required to predict MMMs' performances. The $\mathrm{CO}_{2}$ permeabilities of selected hypothetical polymers are in the range of $90-3 \times 10^{6}$ Barrers and their $\mathrm{CO}_{2} / \mathrm{N}_{2}$ selectivities vary from 2 to 80 . For each hypothetical polymer, we used 5 different MOFs as filler particles, NUJCIE, HAJKOU, LARVIL, IDIWOH, and FEVFUJ. These MOFs are chosen to represent highly $\mathrm{CO}_{2} / \mathrm{N}_{2}$ selective and highly permeable fillers (NUJCIE, HAJKOU, and LARVIL), a highly $\mathrm{CO}_{2}$ permeable filler with low $\mathrm{CO}_{2} / \mathrm{N}_{2}$ selectivity (IDIWOH), and a $\mathrm{N}_{2}$ selective filler with low $\mathrm{CO}_{2}$ permeability (FEVFUJ). If the polymer membrane has a high selectivity for $\mathrm{CO}_{2}$ but low permeability such as the first two hypothetical polymers, adding a MOF can enhance the membrane's permeability with no change in the selectivity. In this limit, the identity of the MOF appears to be unimportant. The effect of MOF identity becomes important for the third polymer which has moderate selectivity and permeability. Highly permeable NUJCIE, HAJKOU, LARVIL, and IDIWOH enhance permeability of

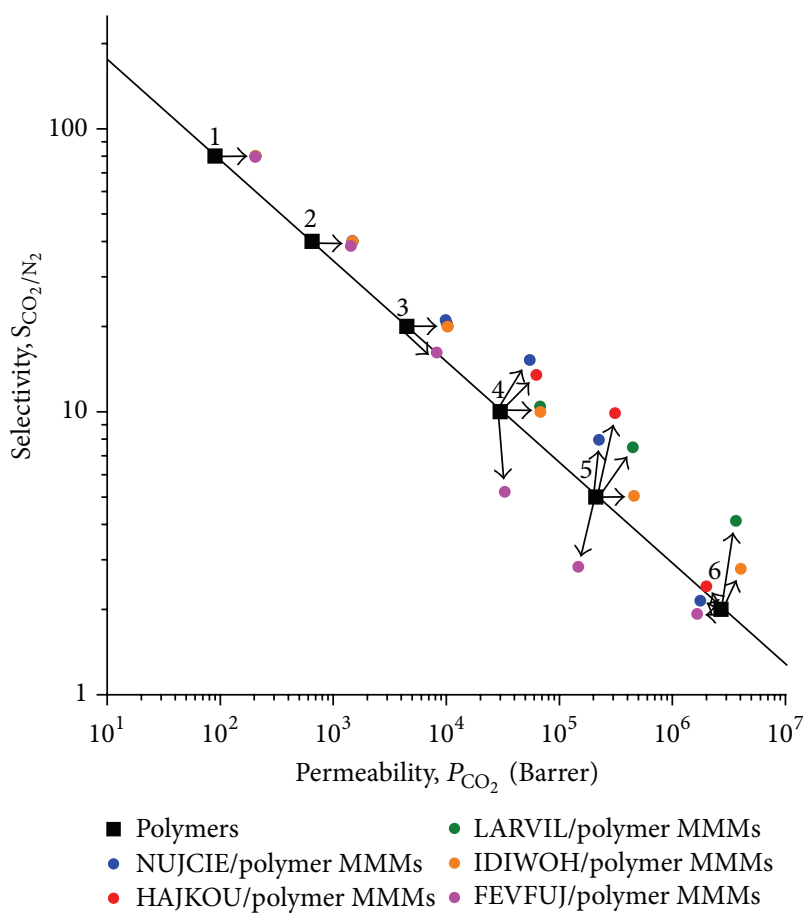

FIgure 5: Predicted $\mathrm{CO}_{2} / \mathrm{N}_{2}$ selectivities and $\mathrm{CO}_{2}$ permeabilities of 30 hypothetical MMMs. Black symbols represent pure hypothetical polymer membranes and color symbols represent the MOF-based MMMs.

the third polymer without changing its selectivity whereas FEVFUJ enhances its $\mathrm{CO}_{2}$ permeability but decreases the $\mathrm{CO}_{2} / \mathrm{N}_{2}$ selectivity. Except FEVFUJ, selected MOF fillers improve both the $\mathrm{CO}_{2}$ permeability and the $\mathrm{CO}_{2} / \mathrm{N}_{2}$ selectivity of the fourth and fifth polymers. This improvement depends on the identity of the MOF. MOFs like NUJCIE and HAJKOU significantly enhance the $\mathrm{CO}_{2} / \mathrm{N}_{2}$ selectivity whereas a MOF like LARVIL significantly enhances the $\mathrm{CO}_{2}$ permeability. The most interesting results are observed for the sixth polymer which has very high permeability but very low selectivity. Highly permeable MOFs, LARVIL and IDIWOH, enhance both the permeability and selectivity of that polymer but all the other MOFs cause a decrease in the $\mathrm{CO}_{2}$ permeability although they increase the selectivity. These results support the idea that there is a wide range of polymers that have moderate selectivity and moderate permeability for which incorporation of an appropriate MOF can yield large separation performance enhancements. The polymers we studied in this work generally have lower $\mathrm{CO}_{2}$ permeabilities but relatively higher $\mathrm{CO}_{2} / \mathrm{N}_{2}$ selectivities compared to MOFs. For polymers that have high permeabilities and low selectivities, separation performances of the MMMs are strongly dependent on the type of MOF.

Finally, it is important to discuss the assumptions of the computational approach that we used to screen MOFbased MMMs for $\mathrm{CO}_{2} / \mathrm{N}_{2}$ separation. Rigid MOF structures were used in our atomically detailed simulations. This assumption has been widely used in almost all molecular simulation studies of MOFs in the literature since flexible 
simulations require significant amount of computational time and resources. We recently investigated the effect of MOF's flexibility on the permeability and selectivity of MOF-based MMMs and showed that flexibility of the MOFs can be neglected as a reasonable approximation if the MOF volume fraction is low and if the MOF is much more permeable than the polymer [30]. The MOFs we studied in this work were highly permeable compared to the polymers shown in Figure 1 and the volume fraction of the MOF in the MMM was set to a low value, 0.3 . Therefore, neglecting the flexibility of MOFs is a reasonable approximation especially for large-scale computational screening studies. Our atomically detailed simulations do not provide any information about the stability of MOF/polymer MMMs. This issue is more likely to be investigated by experimentalists. We checked the stability information for $3 \mathrm{MOFs}$, which were identified to improve both the selectivity and permeability of polymers, from their corresponding experimental synthesis papers. HAJKOU is reported to exhibit high thermal stability and permanent porosity [44], LARVIL is reported to preserve its crystalline integrity at ambient conditions [45], and no information was found for the stability of NUJCIE [46]. We believe that results we presented in this work will motivate several experimental studies to fabricate and test both separation performance and long-term stability of these MOF-based MMMs.

At that point one may think about why not to use MOFs as pure membranes rather than using them as filler particles in polymer membranes. MOFs exhibit high gas permeabilities and high gas selectivities as shown in Figure 1. However, fabrication of MOF membranes requires synthesis of MOFs in bulk amounts at low cost. MOFs are currently synthesized in small amounts at the lab scale and commercially available MOFs are expensive. Furthermore, it is experimentally challenging to fabricate defect-free thin film MOF membranes although recent studies described routes for processing MOF membranes in polymeric hollow fibers [47, 48]. On the other hand, fabrication of MOF-based MMMs on large scales can be done with relatively minor adaptation of existing commercial technology developed for fabrication of polymer membranes at a reasonable cost. Therefore, MOF-based MMMs are expected to be more widely used in gas separation applications compared to thin film MOF membranes in the near future. We believe that results of this study will motivate experiments to fabricate the most promising MOF-based MMMs for $\mathrm{CO}_{2} / \mathrm{N}_{2}$ separations.

\section{Conclusion}

In this study, we combined atomically detailed simulations with the Maxwell model to make predictions for the performances of MOF-based MMMs in $\mathrm{CO}_{2} / \mathrm{N}_{2}$ separations. We first performed atomically detailed simulations to obtain adsorption and diffusion data of $\mathrm{CO}_{2}$ and $\mathrm{N}_{2}$ gases in MOFs. Adsorption, diffusion, and permeation selectivities of MOFs were compared to understand the potential of MOFs in $\mathrm{CO}_{2} / \mathrm{N}_{2}$ separations. Results showed that adsorption selectivity favors $\mathrm{CO}_{2}$ in all MOFs whereas diffusion selectivity can favor either $\mathrm{CO}_{2}$ or $\mathrm{N}_{2}$. As a result, permeation selectivities of MOFs are governed by the diffusion selectivity preference of the materials. Several promising MOFs with high $\mathrm{CO}_{2} / \mathrm{N}_{2}$ selectivities and high $\mathrm{CO}_{2}$ permeabilities were identified. A large number of MOFs were found to be located above the upper bound established for polymers.

Motivated from this result, we examined the separation performances of 700 different MOF-based MMMs composed of 70 MOFs and 10 polymers. This is the largest number of MOF-based MMMs for which computational screening is done to date. Using MOFs as filler particles increased the $\mathrm{CO}_{2}$ permeability of all 10 polymers but the change in selectivity varied with respect to position of the polymer on the upper bound. We showed that, for polymers that have low $\mathrm{CO}_{2}$ permeabilities but high $\mathrm{CO}_{2}$ selectivities, the identity of the MOF used as filler is not important. All MOFs enhanced the $\mathrm{CO}_{2}$ permeabilities of this type of polymers without changing their selectivities. On the other hand, for polymers that have high $\mathrm{CO}_{2}$ permeabilities but low $\mathrm{CO}_{2}$ selectivities, separation properties of the MMMs strongly depend on the identity of the filler particle. Highly selective MOFs were able to increase both the $\mathrm{CO}_{2}$ permeabilities and the $\mathrm{CO}_{2} / \mathrm{N}_{2}$ selectivities of PTMGP and PTMSP. At that point, it is important to note that we only examined a fraction of the MOFs that are reported in CCDC. There are thousands of MOFs in the database that might show better separation properties than the MOFs we studied. It is also important to note that computational methods that we used in this work do not provide any information about the stability of MOF-based MMMs, MOF-polymer interactions, and possible filler agglomeration. Large-scale computational screening approach that we used here will fasten the design and development of new MOF-based MMMs and motivate experimental studies.

\section{Competing Interests}

The authors declare that they have no competing interests.

\section{Acknowledgments}

Financial support provided by the Scientific and Technological Research Council of Turkey (TUBITAK) Grant MAG213M401 is gratefully acknowledged.

\section{References}

[1] H. Yang, Z. Xu, M. Fan et al., "Progress in carbon dioxide separation and capture: a review," Journal of Environmental Sciences, vol. 20, no. 1, pp. 14-27, 2008.

[2] W. J. Koros and R. Mahajan, "Pushing the limits on possibilities for large scale gas separation: which strategies?" Journal of Membrane Science, vol. 175, no. 2, pp. 181-196, 2000.

[3] L. M. Robeson, “The upper bound revisited," Journal of Membrane Science, vol. 320, no. 1-2, pp. 390-400, 2008.

[4] D. Şen, H. Kalipçilar, and L. Yilmaz, "Development of polycarbonate based zeolite 4A filled mixed matrix gas separation membranes," Journal of Membrane Science, vol. 303, no. 1-2, pp. 194-203, 2007.

[5] A. F. Ismail, P. S. Goh, S. M. Sanip, and M. Aziz, "Transport and separation properties of carbon nanotube-mixed matrix 
membrane," Separation and Purification Technology, vol. 70, no. 1, pp. 12-26, 2009.

[6] Y. Dai, J. R. Johnson, O. Karvan, D. S. Sholl, and W. J. Koros, "Ultem/ZIF-8 mixed matrix hollow fiber membranes for $\mathrm{CO}_{2} / \mathrm{N}_{2}$ separations," Journal of Membrane Science, vol. 401402, pp. 76-82, 2012.

[7] J. Sánchez-Laínez, B. Zornoza, Á. Mayoral et al., "Beyond the $\mathrm{H}_{2} / \mathrm{CO}_{2}$ upper bound: one-step crystallization and separation of nano-sized zif-11 by centrifugation and its application in mixed matrix membranes," Journal of Materials Chemistry A, vol. 3, no. 12, pp. 6549-6556, 2015.

[8] D. Q. Vu, W. J. Koros, and S. J. Miller, "Mixed matrix membranes using carbon molecular sieves: I. Preparation and experimental results," Journal of Membrane Science, vol. 211, no. 2, pp. 311-334, 2003.

[9] C. J. Cornelius and E. Marand, "Hybrid silica-polyimide composite membranes: gas transport properties," Journal of Membrane Science, vol. 202, no. 1-2, pp. 97-118, 2002.

[10] B. Zornoza, B. Seoane, J. M. Zamaro, C. Téllez, and J. Coronas, "Combination of MOFs and zeolites for mixed-matrix membranes," ChemPhysChem, vol. 12, no. 15, pp. 2781-2785, 2011.

[11] P. S. Goh, A. F. Ismail, S. M. Sanip, B. C. Ng, and M. Aziz, "Recent advances of inorganic fillers in mixed matrix membrane for gas separation," Separation and Purification Technology, vol. 81, no. 3, pp. 243-264, 2011.

[12] M. W. Anjum, B. Bueken, D. De Vos, and I. F. Vankelecom, "Mil125 (Ti) Based Mixed Matrix Membranes for $\mathrm{CO}_{2}$ Separation from $\mathrm{CH}_{4}$ and $\mathrm{N}_{2}$," Journal of Membrane Science, vol. 502, pp. 21-28, 2016.

[13] T.-H. Bae and J. R. Long, " $\mathrm{CO}_{2} / \mathrm{N}_{2}$ separations with mixedmatrix membranes containing $\mathrm{Mg}_{2}$ (dobdc) nanocrystals," Energy and Environmental Science, vol. 6, no. 12, pp. 3565-3569, 2013.

[14] S. Liu, G. Liu, J. Shen, and W. Jin, "Fabrication of MOFs/PEBA mixed matrix membranes and their application in bio-butanol production," Separation and Purification Technology, vol. 133, pp. 40-47, 2014.

[15] V. Nafisi and M.-B. Hägg, "Gas separation properties of ZIF8/6FDA-durene diamine mixed matrix membrane," Separation and Purification Technology, vol. 128, pp. 31-38, 2014.

[16] L. Zhu, H. Yu, H. Zhang et al., "Mixed matrix membranes containing MIL-53(Al) for potential application in organic solvent nanofiltration," RSC Advances, vol. 5, no. 89, pp. 73068-73076, 2015.

[17] M. Eddaoudi, H. Li, and O. M. Yaghi, "Highly porous and stable metal-organic frameworks: structure design and sorption properties," Journal of the American Chemical Society, vol. 122, no. 7, pp. 1391-1397, 2000.

[18] N. Stock and S. Biswas, "Synthesis of metal-organic frameworks (MOFs): routes to various MOF topologies, morphologies, and composites," Chemical Reviews, vol. 112, no. 2, pp. 933-969, 2012.

[19] E. Adatoz, A. K. Avci, and S. Keskin, "Opportunities and challenges of MOF-based membranes in gas separations," Separation and Purification Technology, vol. 152, pp. 207-237, 2015.

[20] A. Car, C. Stropnik, and K.-V. Peinemann, "Hybrid membrane materials with different metal-organic frameworks (MOFs) for gas separation," Desalination, vol. 200, no. 1-3, pp. 424-426, 2006.

[21] E. V. Perez, K. J. Balkus Jr., J. P. Ferraris, and I. H. Musselman, "Mixed-matrix membranes containing MOF-5 for gas separations," Journal of Membrane Science, vol. 328, no. 1-2, pp. 165173, 2009.
[22] S. Basu, A. Cano-Odena, and I. F. J. Vankelecom, "Asymmetric Matrimid ${ }^{\circledast} /\left[\mathrm{Cu}_{3}(\text { BTC })_{2}\right]$ mixed-matrix membranes for gas separations," Journal of Membrane Science, vol. 362, no. 1-2, pp. 478-487, 2010

[23] S. Basu, A. Cano-Odena, and I. F. J. Vankelecom, "MOF-containing mixed-matrix membranes for $\mathrm{CO}_{2} / \mathrm{CH}_{4}$ and $\mathrm{CO}_{2} / \mathrm{N}_{2}$ binary gas mixture separations," Separation and Purification Technology, vol. 81, no. 1, pp. 31-40, 2011.

[24] C. Duan, G. Kang, D. Liu et al., "Enhanced gas separation properties of metal organic frameworks/polyetherimide mixed matrix membranes," Journal of Applied Polymer Science, vol. 131, no. 17, pp. 8828-8837, 2014.

[25] J. Kim, J. Choi, Y. Soo Kang, and J. Won, "Matrix effect of mixedmatrix membrane containing $\mathrm{CO}_{2}$-selective MOFs," Journal of Applied Polymer Science, vol. 133, no. 1, Article ID 42853, pp. 1-8, 2016.

[26] S. Keskin and D. S. Sholl, "Selecting metal organic frameworks as enabling materials in mixed matrix membranes for high efficiency natural gas purification," Energy and Environmental Science, vol. 3, no. 3, pp. 343-351, 2010.

[27] I. Erucar and S. Keskin, "Computational screening of metal organic frameworks for mixed matrix membrane applications," Journal of Membrane Science, vol. 407-408, pp. 221-230, 2012.

[28] I. Erucar and S. Keskin, "Screening metal-organic frameworkbased mixed-matrix membranes for $\mathrm{CO}_{2} / \mathrm{CH}_{4}$ separations," Industrial and Engineering Chemistry Research, vol. 50, no. 22, pp. 12606-12616, 2011.

[29] G. Yilmaz and S. Keskin, "Molecular modeling of MOF and ZIFfilled MMMs for $\mathrm{CO}_{2} / \mathrm{N}_{2}$ separations," Journal of Membrane Science, vol. 454, pp. 407-417, 2014.

[30] C. Altintas and S. Keskin, "Molecular simulations of porous coordination network-based mixed matrix membranes for $\mathrm{CO}_{2} / \mathrm{N}_{2}$ separations," Molecular Simulation, vol. 41, no. 16-17, pp. 1396-1408, 2015.

[31] F. H. Allen, "The cambridge structural database: a quarter of a million crystal structures and rising," Acta Crystallographica Section B: Structural Science, vol. 58, no. 3, pp. 380-388, 2002.

[32] T. F. Willems, C. H. Rycroft, M. Kazi, J. C. Meza, and M. Haranczyk, "Algorithms and tools for high-throughput geometrybased analysis of crystalline porous materials," Microporous and Mesoporous Materials, vol. 149, no. 1, pp. 134-141, 2012.

[33] L. Sarkisov and A. Harrison, "Computational structure characterisation tools in application to ordered and disordered porous materials," Molecular Simulation, vol. 37, no. 15, pp. 1248-1257, 2011.

[34] A. K. Rappé, C. J. Casewit, K. S. Colwell, W. A. Goddard III, and W. M. Skiff, "UFF, a full periodic table force field for molecular mechanics and molecular dynamics simulations," Journal of the American Chemical Society, vol. 114, no. 25, pp. 10024-10035, 1992.

[35] D. Frenkel and B. Smit, Understanding Molecular Simulation: From Algorithms to Applications, vol. 1, Academic Press, New York, NY, USA, 2001.

[36] S. L. Mayo, B. D. Olafson, and W. A. Goddard III, "DREIDING: a generic force field for molecular simulations," The Journal of Physical Chemistry, vol. 94, no. 26, pp. 8897-8909, 1990.

[37] K. B. Sezginel, A. Uzun, and S. Keskin, "Multivariable linear models of structural parameters to predict methane uptake in metal-organic frameworks," Chemical Engineering Science, vol. 124, pp. 125-134, 2015. 
[38] J. J. Potoff and J. I. Siepmann, "Vapor-liquid equilibria of mixtures containing alkanes, carbon dioxide, and nitrogen," AIChE Journal, vol. 47, no. 7, pp. 1676-1682, 2001.

[39] K. Makrodimitris, G. K. Papadopoulos, and D. N. Theodorou, "Prediction of permeation properties of $\mathrm{CO}_{2}$ and $\mathrm{N}_{2}$ through silicalite via molecular simulations," Journal of Physical Chemistry B, vol. 105, no. 4, pp. 777-788, 2001.

[40] C. E. Wilmer, K. C. Kim, and R. Q. Snurr, "An extended charge equilibration method," Journal of Physical Chemistry Letters, vol. 3, no. 17, pp. 2506-2511, 2012.

[41] D. S. Sholl, "Understanding macroscopic diffusion of adsorbed molecules in crystalline nanoporous materials via atomistic simulations," Accounts of Chemical Research, vol. 39, no. 6, pp. 403-411, 2006.

[42] J. C. Maxwell, A Treatise on Electricity and Magnetism, Dover, 1954.

[43] T. Watanabe and D. S. Sholl, "Accelerating applications of metal-organic frameworks for gas adsorption and separation by computational screening of materials," Langmuir, vol. 28, no. 40, pp. 14114-14128, 2012.

[44] P. Pachfule, Y. Chen, J. Jiang, and R. Banerjee, "Experimental and computational approach of understanding the gas adsorption in amino functionalized interpenetrated metal organic frameworks (MOFs)," Journal of Materials Chemistry, vol. 21, no. 44, pp. 17737-17745, 2011.

[45] Q. Hou, M.-J. Jia, J.-J. Zhao, J. Jin, J.-H. Yu, and J.-Q. Xu, “Two new 3-D photoluminescence metal-organic frameworks based on cubane $\mathrm{Cu}_{4} \mathrm{I}_{4}$ clusters as tetrahedral nodes," Inorganica Chimica Acta, vol. 384, pp. 287-292, 2012.

[46] K. Park, U. Lee, and T. Iwamoto, “Three-dimensional metal complex host with alternating arrangement of the occupied and vacant channels. the crystal structure of $\mathrm{Cd}(\mathrm{Nh} 2 \mathrm{ch}(\mathrm{Ch} 3)$ Ch2nh2) Ni (Cn)(4) Center Dot 0.25 G (G=Ch3c6h5, P(Ch3)(2) C6h4)," Bulletin of the Korean Chemical Society, vol. 17, pp. 919-924, 1996.

[47] A. J. Brown, N. A. Brunelli, K. Eum et al., "Interfacial microfluidic processing of metal-organic framework hollow fiber membranes," Science, vol. 345, no. 6192, pp. 72-75, 2014.

[48] F. Cacho-Bailo, B. Seoane, C. Téllez, and J. Coronas, "ZIF8 continuous membrane on porous polysulfone for hydrogen separation," Journal of Membrane Science, vol. 464, pp. 119-126, 2014. 

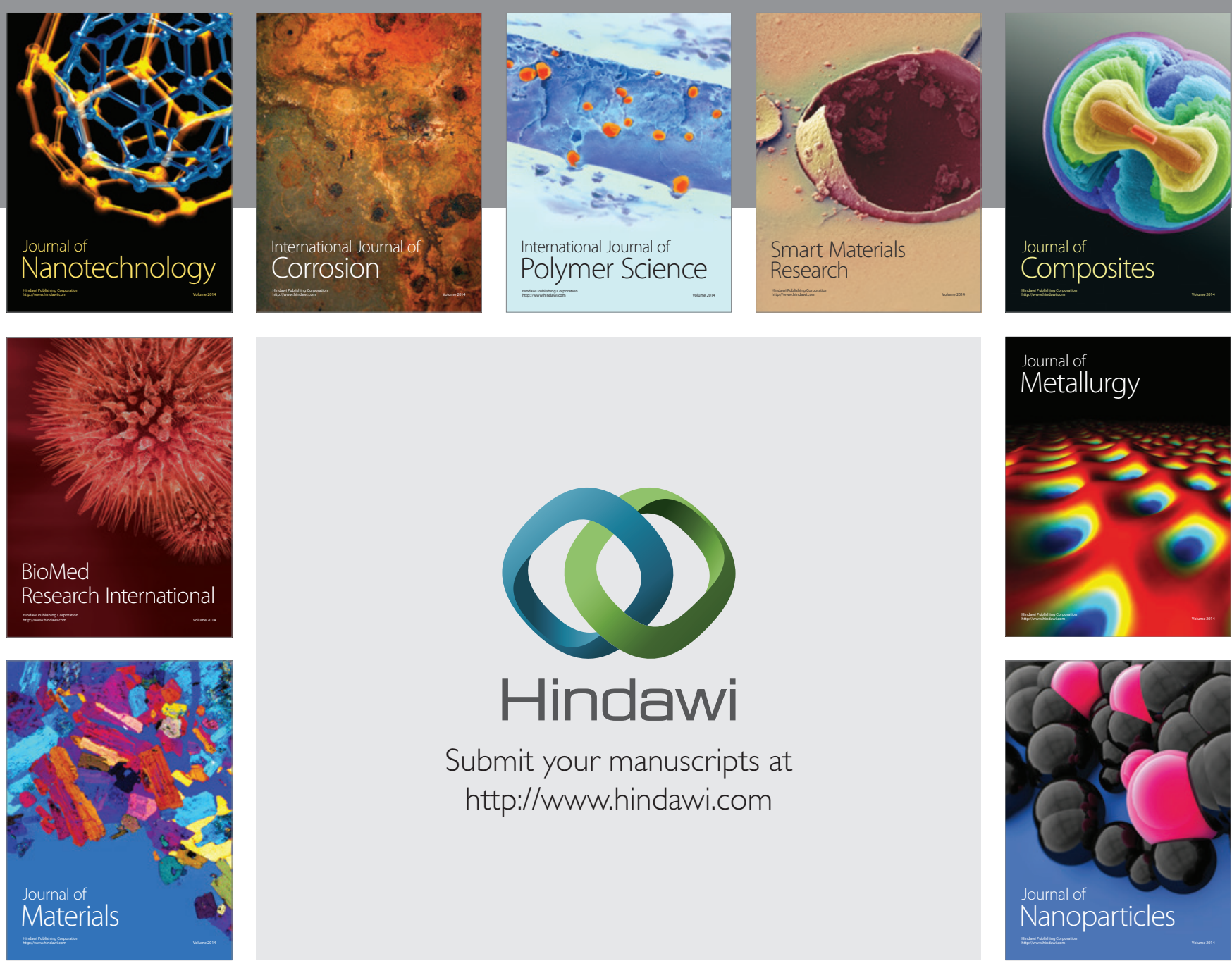

\section{Hindawi}

Submit your manuscripts at

http://www.hindawi.com

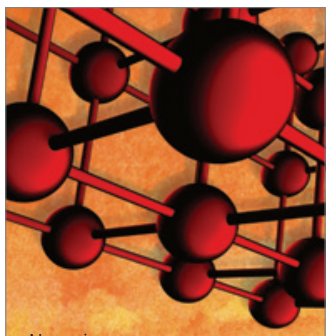

Materials Science and Engineering
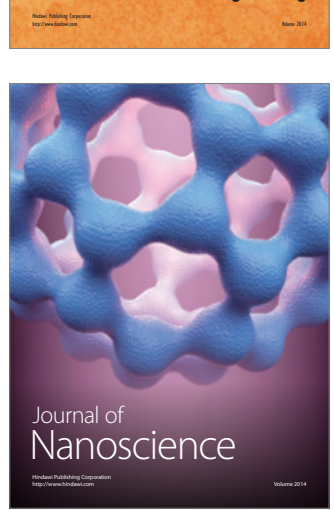
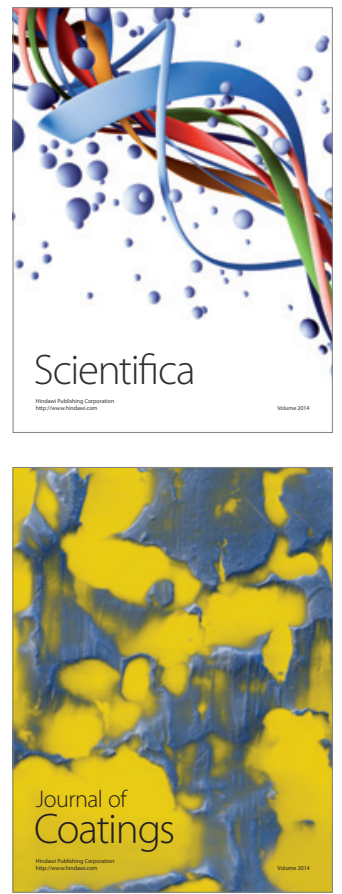
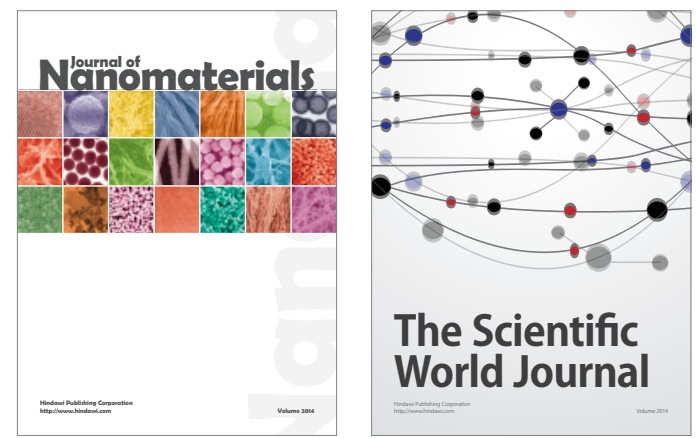

The Scientific World Journal
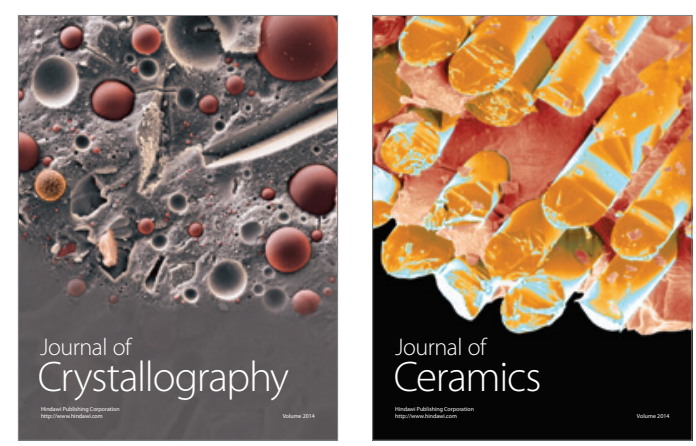
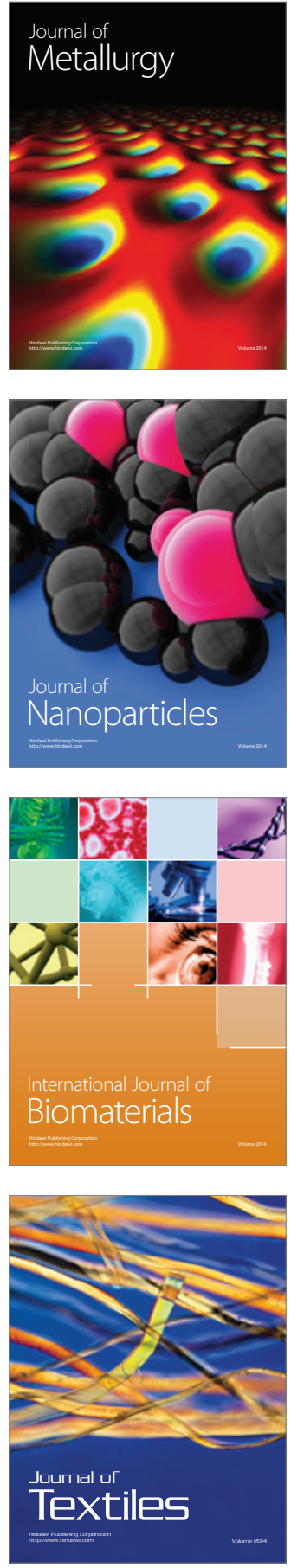